\title{
La reforma procesal penal en el Perú: rompiendo moldes, conquistando metas y enfrentando pendientes
}

\author{
MARÍA ANTONIETA DELGADO MENÉNDEZ*
}

SUMARIO: INTRODUCCIÓN.- I. PRINCIPALES APORTES Y ALCANCES.II. PRINCIPALES LOGROS Y RESULTADOS.- III. PRINCIPALES LIMITACIONES Y DESAFÍOS.- IV. REFLEXIONES FINALES.

\section{INTRODUCCIÓN}

En el año 2004, se promulgó el nuevo Código Procesal Penal (NCPP), con lo cual se cerró una larga fase de incertidumbre política en cuanto a la voluntad del Estado peruano para implementar una reforma largamente anunciada pero varias veces postergada y que, en la actualidad, se encuentra en plena fase de implementación. Ella implica no solo el despliegue de la reforma en los diversos distritos judiciales del país, sino, al mismo tiempo, un intensivo proceso de seguimiento y de monitoreo de los avances y de los nuevos requerimientos que surjan, así como la superación de diversas dificultades de su implementación. En paralelo, este proceso demanda el continuo y permanente perfeccionamiento de los procedimientos institucionales, la capacitación de los operadores del Derecho, la maduración de la comprensión y del entendimiento de los fundamentos político-institucionales de las nuevas normas procesales por parte de los operadores, además de una intensiva y creciente coordinación interinstitucional.

En julio de 2006 el NCPP inició su implementación progresiva en el país; hacia julio de 2010, ha entrado en vigencia en dieciséis distritos judiciales del país, es decir, en el 55\% de los distritos judiciales del Perú, con lo que queda pendiente su implementación en el $45 \%$ de ellos ${ }^{1}$.

* Es profesora ordinaria asociada del curso de Derecho Internacional Privado en la Pontificia Universidad Católica del Perú.

1 El Cronograma de Implementación del NCPP ha sido establecido por los siguientes decretos supremos: 013-2005-JUS, 007-2006-JUS, 005-2007-JUS y 016-2009-JUS. 


\begin{tabular}{|c|c|c|c|c|c|c|c|c|c|c|c|c|c|}
\hline \multicolumn{2}{|c|}{2006} & \multicolumn{2}{|c|}{2007} & \multicolumn{2}{|c|}{2008} & \multicolumn{2}{|c|}{2009} & \multicolumn{2}{|c|}{2010} & \multicolumn{2}{|c|}{2011} & \multicolumn{2}{|c|}{2012} \\
\hline 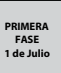 & Huaner & 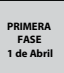 & L L LUGGrad & 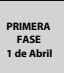 & 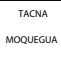 & 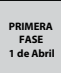 & $\begin{array}{c}\text { TUMBSS } \\
\text { PURA } \\
\text { LAMBANEFEUE }\end{array}$ & 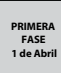 & 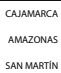 & 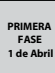 & 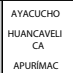 & 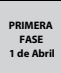 & $\begin{array}{l}\text { Ucaryal } \\
\text { Lonfro }\end{array}$ \\
\hline & & & & 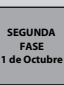 & AEEQUPA & 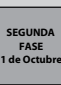 & 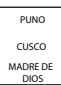 & 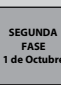 & \begin{tabular}{|l} 
ANGSH \\
SANTA
\end{tabular} & 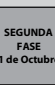 & $\begin{array}{l}\text { Huthuco } \\
\text { passco } \\
\text { sunin }\end{array}$ & 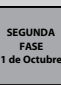 & 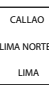 \\
\hline & & & & & & 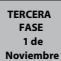 & $\begin{array}{l}\text { ICA } \\
\text { CANEEE }\end{array}$ & & & & & & \\
\hline
\end{tabular}

\section{PRINCIPALES APORTES Y ALCANCES}

En el Perú, el NCPP marca el inicio de una reforma procesal penal garantista que apunta a mejorar de manera efectiva el sistema de administración de justicia y que implica una verdadera transformación en el proceso penal del país. Entre sus objetivos, se cuentan reordenar el sistema de enjuiciamiento penal, acercarse al ideal de justicia pronta y cumplida, potenciar el derecho a la defensa y asegurar, en lo posible, la vigencia de los derechos humanos cuando el Estado hace valer su pretensión punitiva ${ }^{3}$.

Los alcances de la reforma se caracterizan fundamentalmente por los siguientes elementos ${ }^{4}$ :

\section{Poner mayor énfasis en lo acusatorio, y en lo adversarial y contradictorio. Ello implica la introducción de importantes cambios en la estructura funcional, mecanismos de tramitación de la carga de trabajo, cultura organizacional $y$, en general, un cambio de mentalidad en todas las instituciones vinculadas con el servicio de justicia, pero principalmente en el Poder Judicial, en el Ministerio Público y en la Policía Nacional.}

Lo anterior involucra el abandono de la estructura inquisitiva y reservada y la aplicación de los principios de oralidad, inmediación, contradicción y publicidad, base para el desarrollo del juicio oral como etapa central del proceso penal común. Dado que la oralidad y la inmediación son ejes esenciales del juzgamiento, el NCPP establece que toda petición o cuestión propuesta en la audiencia, la recepción de las pruebas y, en términos generales, toda intervención de quienes participen en ella deba ser argumentada oralmente y en presencia del juez, por lo que queda prohibido dar lectura a escritos presentados con tal fin. Asimismo, prescribe reglas claras para que las resoluciones sean dictadas y fundamentadas oralmente durante el transcurso de las audiencias, especialmente cuando se trate de incidentes promovidos durante el juicio, con lo que

2 “Balance y desafíos de la reforma procesal penal en el Perú». Lima: Ministerio Público, 2010. En 4 www.mpfn.gob.pe/ncpp/art_interes.php, p. 7.

3 «Reporte de la justicia en Perú 2008-2009». Santiago de Chile: Centro de Justicia para las Américas - CEJA, 2009. En KwWw.cejamericas.org/reporte/muestra_pais3.php?idioma=espanol\&pais=PERU \&tipreport=REPORTE4\&seccion=PROPENA4, p. 147.

4 “Código Procesal Penal. Manuales operativos. Normas para la implementación». Lima: Academia de la Magistratura, 2008. En http://blog.pucp.edu.pe/media/1991/20080701-Libro_codi_proce_ pen2008.pdif, pp. 11-12. 
se eliminan formalismos innecesarios. También prevé la posibilidad de registrar las audiencias electrónicamente.

\section{Establecer nuevos roles para los operadores del sistema de justicia, en especial para jueces, fiscales y policías.}

La oralidad requiere delimitar y separar las funciones de investigación y juzgamiento, lo cual, en el nuevo modelo, exige dejar de lado la figura del juez instructor. Por lo tanto, una de las innovaciones más relevantes del NCPP radica en que establece una etapa de investigación flexible y única a cargo del fiscal, durante la que el juez ya no investiga.

Asimismo, el NCPP ha definido con bastante precisión las competencias del Ministerio Público y de la Policía Nacional en el ámbito de la investigación del delito. Esta última queda a cargo del Ministerio Público, quien la debe llevar a cabo con el apoyo operativo, técnico y científico de la Policía Nacional. En esta etapa del nuevo proceso, los jueces únicamente cumplen la función de garantes de las partes involucradas, a fin de decidir sobre las posibles afectaciones a sus derechos o de dictar medidas de protección o de tutela, según corresponda. El rol de la policía se limita entonces solo a la investigación preliminar; por ello, las diligencias de la investigación preparatoria no podrán repetirse una vez formalizada la investigación, salvo que ello resulte indispensable por haberse detectado un grave defecto en su actuación o porque, ineludiblemente, deba completarse como consecuencia de la incorporación de nuevos elementos de convicción. Asimismo, en el informe que la policía presente al fiscal, esta debe abstenerse de hacer calificaciones jurídicas y de imputar responsabilidades.

El principio acusatorio que sustenta al NCPP implica la repartición de tareas en el proceso penal, durante el cual el juzgamiento y la acusación recaen sobre diferentes sujetos procesales. Por ello, el juez no puede realizar investigaciones por cuenta propia, sino que estas son responsabilidad del fiscal de turno. El NCPP establece dos tipos de órgano jurisdiccional: el juez de la investigación preparatoria y el juez de juzgamiento. El rol del primero de ellos es controlar la seguridad y los plazos de la investigación, autorizar medidas cautelares, actuar de prueba anticipada y conducir la investigación preliminar en la fase intermedia. Por su parte, el juez de juzgamiento tiene como único rol el de conducir el juicio oral a través de un órgano colegiado o unipersonal, según sea el caso.

\section{Buscar mayor celeridad en los procesos, consagrar procedimientos más ágiles y promover una gestión más eficiente de los despachos fiscal y judicial para reducir la duración de los procesos.}

Con el objetivo de favorecer la celeridad de los procesos, durante la etapa del juicio oral o la fase de juzgamiento se deben observar los principios de continuidad y concentración de los actos del juicio. La audiencia

LA REFORMA PROCESAL PENAL EN EL PERÚ:

ROMPIENDO MOLDES, CONQUISTANDO METAS Y ENFRENTANDO PENDIENTES 
debe desarrollarse de forma continua e incluso podría prolongarse a lo largo de sesiones sucesivas hasta su conclusión.

Siempre y cuando las decisiones sean adoptadas durante ellas, las audiencias promueven una pronta resolución de los procesos y, por lo tanto, tornan más veloz el sistema de justicia. Es importante desarrollar ininterrumpidamente todas las actuaciones de las partes durante ellas. Ello redundará en la mejor calidad de las resoluciones y, por ende, en la reducción del número de impugnaciones y apelaciones.

\section{Diferenciar y separar las funciones jurisdiccionales de las administrativas.}

La organización del nuevo sistema procesal penal requiere separar las funciones jurisdiccionales de las meramente administrativas. Ello supone que la gestión del sistema sea debidamente profesionalizada para estar en capacidad de brindar el soporte logístico, de infraestructura y de personal necesario para que jueces, fiscales, policías y defensores públicos cumplan cabalmente sus roles y funciones.

Asimismo, implica una nueva estructura del despacho judicial y fiscal basada en la organización corporativa, el diseño de una nueva gestión judicial y fiscal orientada hacia la transparencia, la celeridad y la eficacia, y a la eficiencia en la solución de los casos penales.

\section{Permitir la desjudicialización de las causas: el «efecto embudo».}

El nuevo modelo procesal penal contempla una serie de mecanismos alternativos de resolución de los casos (la facultad de calificar las denuncias y las denominadas salidas alternativas) cuya adecuada aplicación, a cargo del Ministerio Público, evita que todos lleguen a sede judicial55.

En efecto, el NCPP, en su artículo 334, prevé la facultad de calificación de la denuncia a cargo del fiscal, en cuya virtud este puede disponer el archivamiento de los casos cuando: (a) el hecho denunciado no constituya delito; (b) no sea justiciable penalmente; o (c) se presenten causas de extinción legalmente previstas.

Más aún, luego de haber concluido la investigación preparatoria, el fiscal, en la etapa intermedia y conforme con el artículo 344 del NCPP, puede solicitar al juez de la investigación preparatoria el sobreseimiento de la causa cuando: (a) el hecho objeto de ella no se hubiere realizado o no resultase atribuible al imputado; (b) el hecho no sea típico o concurra una causa de justificación, de inculpabilidad o de no punibilidad; (c) la acción penal se hubiere extinguido; o (d) razonablemente no exista la posibilidad de incorporar nuevos datos a la investigación y no hubiere elementos de convicción suficientes para solicitar, con fundamentos, el enjuiciamiento del imputado. 


\section{Ofrecer la aplicación de salidas alternativas.}

Adicionalmente a la posibilidad de archivar determinados casos o de solicitar su sobreseimiento, según la etapa procesal en la que se decida su desestimación, el fiscal también cuenta con otro grupo de herramientas denominadas salidas alternativas, que tienen por finalidad no solo procurar mejores soluciones penales para las partes involucradas en un caso, sino, a la par, contribuir a la pronta resolución de los conflictos que llegan al Sistema de Justicia Penal. El objetivo principal es evitar que todas las causas arriben a una sede judicial y que, en consecuencia, se racionalicen los recursos del sistema ${ }^{6}$.

Ello posibilita que la investigación del delito no sea solamente la búsqueda de medios probatorios incriminatorios sino también exculpatorios, lo cual promueve comunicación y coordinación continuas y fluidas entre el Ministerio Público y la Defensa de Oficio. Puesto que ambas instituciones están facultadas para proponer los casos y las fórmulas para la aplicación de salidas alternativas, se logrará un verdadero contexto de negociación entre las partes y se asegurará, durante el proceso, la igualdad de armas entre estas.

Las salidas alternativas previstas en el NCPP, entre las cuales figuran el principio de oportunidad, los acuerdos reparatorios, el proceso inmediato y el proceso de terminación anticipada, son mecanismos procesales diseñados no solo para flexibilizar, economizar y descongestionar el sistema de justicia penal (y por ende para tornar más efectivo su funcionamiento en términos de celeridad y resultados), sino también para ofrecer mejores y más rápidas soluciones a los conflictos penales.

En tal sentido, su aplicación se sustenta principalmente en?

- la necesidad de racionalizar la persecución penal pública frente a los escasos recursos disponibles, lo cual ayudará a descongestionar el sistema de justicia penal al focalizarlo en delitos de mayor gravedad;

- la conveniencia social de excluir la respuesta penal tradicional y el contacto con el sistema carcelario cuando se trate de personas con altas posibilidades de reinserción; y

- el reconocimiento de la víctima como sujeto activo dentro del proceso y la consecuente protección y satisfacción de sus intereses, especialmente referidos a la reparación de los daños causados por el ilícito penal.

\section{LA REFORMA} PROCESAL PENAL EN EL PERÚ: ROMPIENDO MOLDES, CONQUISTANDO METAS Y ENFRENTANDO PENDIENTES 


\section{Salidas alternativas previstas en el NCPP}

\begin{tabular}{|c|c|}
\hline $\begin{array}{l}\text { Principio de } \\
\text { oportunidad } \\
\text { Puede invocarse de } \\
\text { oficio o a pedido del } \\
\text { imputado y con su } \\
\text { consentimiento. }\end{array}$ & $\begin{array}{l}\text { Permite que el fiscal se abstenga de ejercitar la acción penal } \\
\text { cuando: } \\
\text { - El agente haya sido afectado gravemente por las consecuen- } \\
\text { cias de su delito, culposo o doloso, siempre que este último } \\
\text { sea reprimido con pena privativa de libertad prevista no ma- } \\
\text { yor de cuatro años y que la pena resulte innecesaria. } \\
\text { - Se trate de delitos que no afecten gravemente el interés } \\
\text { público, excepto cuando el extremo mínimo de la pena sea } \\
\text { superior a dos años de pena privativa de libertad o hubieran } \\
\text { sido cometidos por un funcionario público en ejercicio de su } \\
\text { cargo. En este caso, es necesario que el agente haya reparado } \\
\text { los daños y perjuicios ocasionados o que exista acuerdo con } \\
\text { el agraviado. } \\
\text { - El fiscal pueda apreciar, conforme con las circunstancias } \\
\text { del hecho y con las condiciones personales del denunciado, } \\
\text { que concurren supuestos atenuantes (error de tipo, de pro- } \\
\text { hibición, de comprensión culturalmente condicionada, ten- } \\
\text { tativa, responsabilidad restringida por edad y complicidad } \\
\text { primaria y secundaria) y que advierta que no existe interés } \\
\text { público gravemente comprometido en su persecución (ex- } \\
\text { cepto cuando el delito tenga prevista una sanción superior } \\
\text { a cuatro años de pena privativa de la libertado o haya sido } \\
\text { cometido por un funcionario público en ejercicio de sus fun- } \\
\text { ciones). En este caso, también es necesario que el agente } \\
\text { haya reparado los daños y perjuicios. }\end{array}$ \\
\hline $\begin{array}{l}\text { Los acuerdos } \\
\text { reparatorios }\end{array}$ & $\begin{array}{l}\text { Son decisiones adoptadas entre el imputado y la víctima en } \\
\text { torno a la reparación de los daños que se hayan derivado de } \\
\text { la comisión del delito. Procede en casos de lesiones leves, } \\
\text { hurto simple, de uso y de ganado, apropiación ilícita común, } \\
\text { sustracción de bien propio, apropiación irregular y de prenda, } \\
\text { estafa, de defraudación, administración fraudulenta, daño } \\
\text { simple y libramiento indebido de cheques. Es independiente } \\
\text { a la aplicación del principio de oportunidad. Una vez celebra- } \\
\text { dos, el fiscal se abstendrá de ejercitar la acción penal; si esta } \\
\text { ya hubiese sido promovida, el juez de la investigación pre- } \\
\text { paratoria, previa la correspondiente audiencia, puede dictar } \\
\text { auto de sobreseimiento. }\end{array}$ \\
\hline El proceso inmediato & $\begin{array}{l}\text { Si bien no es en estricto una salida alternativa, sí contribuye a } \\
\text { la celeridad procesal y, por ende, al descongestionamiento del } \\
\text { sistema. El fiscal puede solicitar esta vía cuando: } \\
\text { - el imputado haya sido sorprendido y detenido en flagrante } \\
\text { delito o haya confesado su comisión; o } \\
\text { - los elementos de convicción acumulados durante las dili- } \\
\text { gencias preliminares y previas al interrogatorio del imputado } \\
\text { sean evidentes. } \\
\text { - Este proceso permite al fiscal formular directamente la acu- } \\
\text { sación; no obstante, antes de su formulación, el imputado } \\
\text { puede solicitar que se inicie un proceso de terminación } \\
\text { anticipada. }\end{array}$ \\
\hline
\end{tabular}


El proceso de terminación anticipada
Es un mecanismo de simplificación procesal fundado en el consenso. Su objetivo es la conclusión antelada del proceso penal. Para su procedencia, se requiere que, antes de la formulación de la acusación, el fiscal y el imputado presenten una solicitud conjunta y un acuerdo provisional sobre la pena y la reparación civil, así como respecto de las demás consecuencias accesorias de la comisión del delito. En la correspondiente audiencia de terminación anticipada (que tiene el carácter de privada), si el fiscal y el imputado llegan a un acuerdo acerca de las circunstancias del hecho punible, de la pena, de la reparación civil y de las demás consecuencias, el juez puede dictar una sentencia anticipada para aprobar el acuerdo.

\section{Favorecer la transparencia y legitimidad de los procesos, permitir que las partes intervengan con igualdad de fuerzas y condiciones, y promover mayor participación de víctimas e imputados.}

El NCPP se sustenta en el principio de publicidad: impulsa así mayor difusión y transparencia en los procesos y mayor legitimidad en el sistema de justicia. Prescribe como regla general que el juicio se desarrolle en forma pública, lo cual representa un instrumento fundamental de participación ciudadana y de control popular de los poderes jurisdiccionales y acusatorios fiscales. Así se garantiza que cualquier persona o entidad tenga conocimiento de cómo se realiza un juicio oral y controle que no se registren actuaciones y decisiones arbitrarias por parte de jueces y fiscales.

Asimismo, establece que el juicio oral se debe realizar con la presencia ininterrumpida de los jueces, del fiscal y de las demás partes, y establece soluciones en caso de que estas se ausenten (no cabe por tanto la delegación de funciones).

El NCPP supone también el otorgamiento de una nueva orientación basada en la igualdad de condiciones para las partes y el derecho de defensa al imputado en un plano igualitario dentro del marco del debido proceso. El principio de contradicción que fundamenta el NCPP permite que las partes puedan intervenir con igualdad de fuerzas y condiciones dentro del juzgamiento y que realicen con libertad todo lo posible para desvirtuar o controvertir el caso de la contraparte. Así se garantiza la inviolabilidad del derecho de defensa.

\section{Brindar mayor seguridad jurídica para consagrar la libertad del imputado como regla general del proceso y la excepcionalidad de la prisión preventiva.}

El NCPP busca un equilibrio entre el valor garantía y el valor seguridad. Brinda una serie de posibilidades para que el imputado afronte el proceso dentro del marco de las garantías constitucionales y el cumplimiento de los tratados de derechos humanos. Al mismo tiempo, sin embargo, posibilita al sistema de justicia penal la utilización de las herramientas

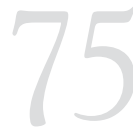

LA REFORMA

PROCESAL PENAL

EN EL PERÚ:

ROMPIENDO

MOLDES,

CONQUISTANDO

METAS Y

ENFRENTANDO

PENDIENTES 
necesarias para redefinir los conflictos penales y cumplir con la obligación del Estado de garantizar la seguridad ciudadana.

Para realizar una imputación o iniciar un proceso, el sistema acusatorio que fundamenta al NCPP exige que existan indicios suficientes de que un individuo ha cometido un hecho constitutivo de delito, no solo meras sospechas. Asimismo, el NCPP consagra la libertad del imputado como regla general del proceso y la excepcionalidad de la prisión preventiva, que debe sujetarse a requisitos específicos contemplados de manera taxativa en el nuevo código. Cabe resaltar que una expectativa medular con respecto a las reformas procesal penales latinoamericanas se relaciona con la racionalización y el uso excepcional de la prisión preventiva, en aras de: (a) el debido cumplimiento de los acuerdos internacionales suscritos y ratificados por nuestros países, que prescriben el debido respeto a los derechos humanos de las personas, incluyendo los de las personas investigadas o procesadas por la comisión de delitos; y (b) combatir el hacinamiento de las cárceles, que atenta contra la seguridad y la gestión penitenciarias, la salud y alimentación de los internos, así como contra un adecuado tratamiento para su reinserción ${ }^{8}$.

Sobre la misma línea, se establece un proceso común para todos los delitos; con ello se elimina el proceso sumario, que es sumamente inquisitivo y que, lejos de ser una excepción, se había convertido en una regla aplicable casi al $90 \%$ de los tipos penales.

\section{Transferir las experiencias positivas en la implementación del nuevo proceso penal no solo a los nuevos aplicadores del NCPP, sino también a otros procesos de reforma, y contribuir así a ampliar las bases para la implementación sucesiva de las medidas de reforma propuestas por la COMISIÓN ESPECIAL PARA LA REFORMA INTEGRAL DE LA ADMINISTRACIÓN DE JUSTICIA?} Un buen ejemplo constituye la nueva reforma procesal laboral ${ }^{10}$ que se está iniciando en el país y que está sustentada sobre los mismos principios ejes de la reforma procesal penal.

8 «Reporte de la justicia en Perú 2008 - 2009». Ob. cit., p. 49.

9 La Comisión Especial para la Reforma Integral de la Administración de Justicia, o CeRIAJus, fue creada mediante la ley 28083, a su vez publicada el 04 de octubre de 2003 en el diario oficial El Peruano, con la finalidad de elaborar el Plan Nacional de Reforma Integral de la Administración de Justicia, que encerrara una propuesta global y concertada de reforma.

10 El 15 de enero de 2010 se publicó la Nueva Ley Procesal del Trabajo del Perú, número 29497, cuya implementación se realizará de manera progresiva a partir de julio de 2010. 


\section{PRINCIPALES LOGROS Y RESULTADOS}

A la fecha, se registran los siguientes resultados principales ${ }^{11}$ :

\section{Los procesos se resuelven con mayor rapidez.}

Uno de los principales logros de la implementación del NCPP es la reducción del tiempo de duración de los procesos penales. Antes de su aplicación, se tenía que esperar varios años para la terminación de los procesos sin que hubiera solución alguna. Ahora un caso se puede resolver incluso a lo largo de algunas horas. Lamentablemente, salvo en casos muy puntuales, no existe una línea de base que nos permita conocer con precisión la duración de los procesos antes de la entrada en vigencia del NCPP.

El siguiente cuadro elaborado por el Ministerio Público grafica la situación luego de la entrada en vigor del NCPP:

\section{Casos resueltos con aplicación del NCPP por tipo de delito ${ }^{12}$}

\begin{tabular}{|l|l|l|l|}
\hline 01 & Hurto agravado (18/02/2008) & Huaura & 05.15 horas \\
\hline 05 & Hurto agravado (13/06/2008) & Tacna & 07.45 horas \\
\hline 09 & Hurto agravado $(07 / 02 / 2008)$ & La Libertad & 15.00 horas \\
\hline 11 & Robo agravado (19/09/2007) & Huaura & 19.00 horas \\
\hline 12 & Hurto agravado (24/09/2007) & La Libertad & 20.00 horas \\
\hline 14 & Violación sexual (12/07/2007) & Huaura & 26.22 horas \\
\hline 16 & Actos contra el pudor (21/09/2007) & Huaura & 30.00 horas \\
\hline 16 & Robo agravado (01/07/2008) & Tacna & 30.00 horas \\
\hline 17 & Contra la vida, cuerpo y salud (07/07/2007) & Huaura & 36.00 horas \\
\hline 19 & Robo agravado (25/06/2007) & Huaura & 44.00 horas \\
\hline 20 & Tráfico drogas-microcomerc. (08/05/2008) & Huaura & 12.12 días \\
\hline 21 & Tráfico drogas-microcomerc. (06/06/2008) & Huaura & 12.23 días \\
\hline 23 & Chantaje (12/05/2007) & La Libertad & 18.00 días \\
\hline 24 & Favorece consumo de drogas (12/12/2007) & La Libertad & 33.00 días \\
\hline 25 & Robo agravado (09/04/2007) & La Libertad & 72.00 días \\
\hline
\end{tabular}

11 «Proyecto de informe de resultados generales sobre el Código Procesal Penal». Lima: Comisión Especial de Implementación del Código Procesal Penal, 2010, pp. 5-70.

12 «Ranking de casos resueltos con aplicación del Código Procesal Penal». Lima: Ministerio Público, 2010. En www.mpfn.gob.pe/ncpp/Ranking_cr.phpp.

LA REFORMA PROCESAL PENAL EN EL PERÚ: ROMPIENDO MOLDES, CONOUISTANDO METAS Y ENFRENTANDO PENDIENTES 
Asimismo, existe información valiosa compilada por el Ministerio Público que da cuenta de la variación y de la evolución de la duración de los procesos penales en los primeros tres años de aplicación del NCPP.

\section{Casos resueltos con aplicación del NCPP por tipo de proceso}

\begin{tabular}{|l|c|c|c|}
\hline \multirow{2}{*}{ Proceso } & \multicolumn{3}{c|}{ Duración promedio (días) } \\
\cline { 2 - 4 } & $\begin{array}{c}\text { 1er. año de } \\
\text { reforma }\end{array}$ & $\begin{array}{c}\text { 2do. año de } \\
\text { reforma }\end{array}$ & $\begin{array}{c}\text { 3er. año de } \\
\text { reforma }\end{array}$ \\
\hline Acuerdo reparatorio & 153 & 166 & 83 \\
\hline Archivo & 140 & 137 & 84 \\
\hline Principio de oportunidad & 253 & 226 & 111 \\
\hline Proceso común (condenatoria) & 315 & 205 & 194 \\
\hline Proceso común (absolutoria) & & 229 & 182 \\
\hline Proceso inmediato & 196 & 177 & 102 \\
\hline Sobreseimiento & 215 & 114 & 26 \\
\hline Terminación anticipada & 14 & 42 & 152 \\
\hline Derivados & & & 132 \\
\hline
\end{tabular}

Elaboración: Ministerio Público / Fuente: Sistema de Gestión Fiscal (SGF) ${ }^{13}$

Por su parte, la Comisión Especial de Implementación del Código Procesal Penal (CEICPP) también reporta importante información relativa a la duración de los procesos luego de iniciada la aplicación del NCPP. La más completa pertenece al distrito judicial de Huara, dada la existencia de una línea de base elaborada al iniciarse el proceso de implementación del NCPP. Los datos refieren que en Huara, hacia julio de 2006, bajo el código de procedimientos penales anterior, en promedio un proceso ordinario tomaba 28 meses (835 días), mientras que uno sumario duraba 23 meses (694 días) ${ }^{14}$.

Si se comparan los datos contenidos en el cuadro anterior con los datos de los distritos de Huaura, La Libertad, Tacna, Moquegua, Arequipa, Tumbes, Piura, Lambayeque, Cusco, Puno y Madre de Dios reportados por la Secretaría Técnica de la CEICPP a marzo de 2010, se pueden advertir interesantes logros en la reducción del tiempo de resolución de los casos penales ${ }^{15}$. 
Línea base de tiempos procesales en el DJ de Huaura bajo el Código de Procedimientos Penales

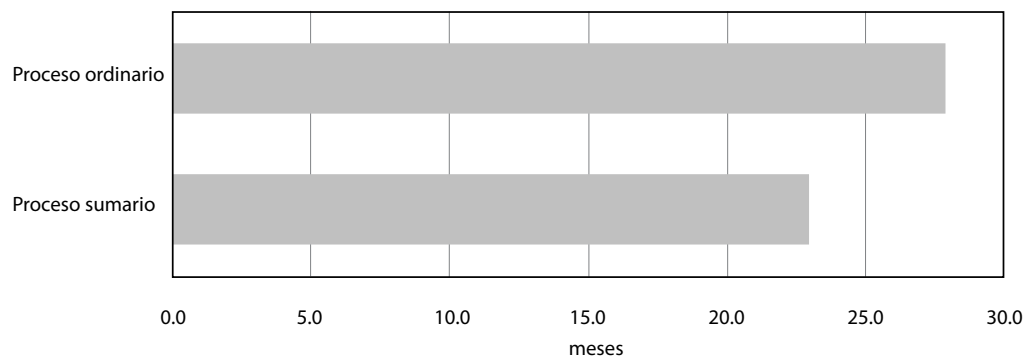

\section{LA REFORMA}

PROCESAL PENAL

EN EL PERÚ:

ROMPIENDO

MOLDES,

CONQUISTANDO

METASY

ENFRENTANDO

Elaboración: ST CEI CPP

Fuente: Estudio para la determinación de la línea de base del tiempo de procesamiento de casos en el distrito judicial PENDIENTES

\section{Tiempo promedio de resolución de casos en el nuevo Código Procesal Penal}

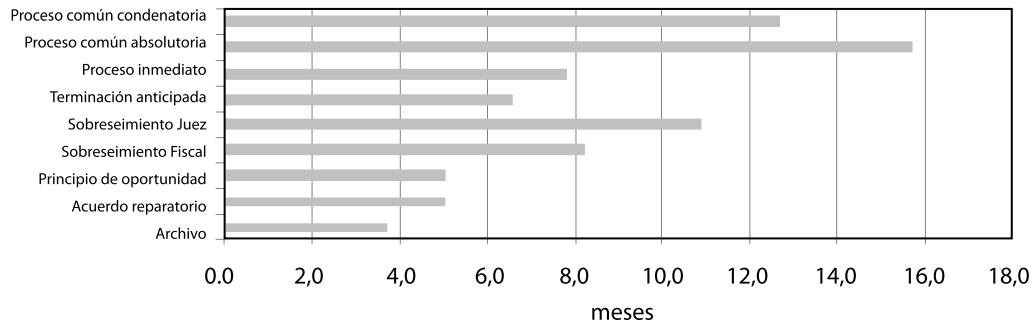

Elaboración: ST CEI CPP

Fuente: Ministerio Público - Información desde la entrada en vigencia del NCPP a marzo de 2010. CPP, julio de 2007.

2. Se registra un mejor nivel de atención de los casos, que conlleva una reducción de la carga procesal.

Entre las principales deficiencias del Código de Procedimientos Penales de 1940, figuran la limitada capacidad de atención que genera en el sistema de justicia penal. Durante el período comprendido entre 1996 y 2005, el nivel de atención (nivel de resolución de los casos en un año) era en promedio de tan solo $43 \%{ }^{16}$. Ello implica que, del número total de casos que ingresaban cada año, solo se atendían o resolvían menos de la mitad, lo cual generaba una sucesiva e incesante acumulación de carga procesal.

La aplicación del NCPP ha comportado un importante incremento en el nivel de atención de casos en los distritos judiciales en los que ha entrando en vigencia, tal como se observa en el siguiente cuadro:

16 Ibíd. p. 11. El informe ha tomado como referencia el documento «Carga y descarga procesal en el Poder Judicial, 1996-2005». Debe considerar que el NCPP inició su vigencia en el distrito judicial de Huaura en julio de 2006. 


\section{Nivel de atención de casos penales con el Código Procesal Penal}

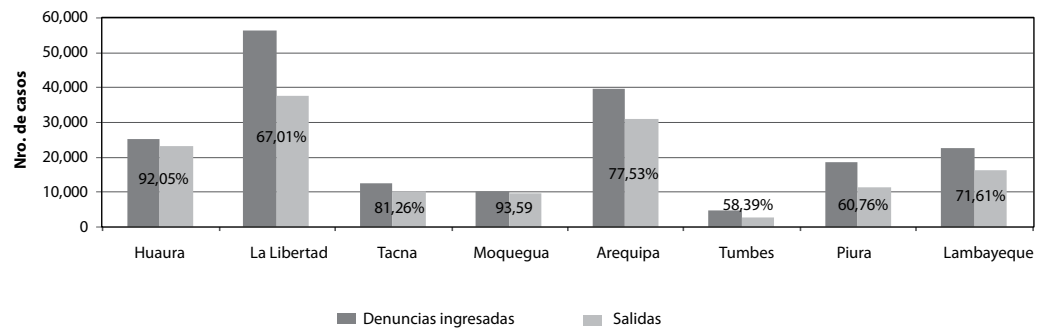

Elaboración: ST CEI CPP

Fuente: Ministerio Público - Información desde la entrada en vigencia del NCPP en los distritos judiciales a marzo de 2010.

Un año después de la implementación de NCPP en el distrito judicial de Huara, se registra una significativa reducción de la carga procesal: se pasó de 10,295 expedientes a $6,451^{17}$.

El siguiente cuadro elaborado por el Ministerio Público muestra el porcentaje de causas que ingresaron y, al mismo tiempo, fueron concluidas durante 2009:

Denuncias y casos concluidos del 01/01/2009 al 30/11/2009/18

\begin{tabular}{|l|c|c|c|}
\hline $\begin{array}{c}\text { Tipo de } \\
\text { proceso }\end{array}$ & $\begin{array}{c}\text { Denuncias } \\
\text { ingresadas }\end{array}$ & $\begin{array}{c}\text { Denuncias } \\
\text { concluidas }\end{array}$ & $\%$ \\
\hline Huaura & 7.226 & 3.723 & 51.52 \\
\hline La Libertad & 18.840 & 7.103 & 37.70 \\
\hline Tacna & 5.698 & 3.270 & 57.39 \\
\hline Moquegua & 4.934 & 3.208 & 65.02 \\
\hline Arequipa & 22.891 & 12.422 & 54.27 \\
\hline Lambayeque & 15.048 & 4.654 & 50.86 \\
\hline Piura & 11.853 & 4.498 & 37.95 \\
\hline Tumbes & 3.025 & 1.425 & 47.11 \\
\hline Cusco & 1027 & 83 & 8.08 \\
\hline Puno & 1022 & 115 & 11.25 \\
\hline Madre de Dios & 378 & 13 & 3.44 \\
\hline
\end{tabular}

17 «Informe anual de implementación del NCPP en el distrito judicial de Huara». Lima: Ministerio de Justicia, 2008. En <www.minjus.gob.pe/cpp/Libro_Ministerio_de_Justicia_04-03-2008.pdf>, pp. 6465.

18 "Balance y desafíos de la Reforma Procesal Penal en el Perú». Ob. cit., p. 43. 


\section{Ha habido una drástica disminución de las quejas formuladas contra los magistrados.}

Mientras que en el período comprendido entre julio de 2005 y junio de 2006 se formularon 58 quejas, en el período comprendido entre julio de 2006 y junio de 2007 se presentaron solamente seis.

\section{Se ha registrado un positivo e importante impacto del nuevo modelo procesal penal sobre el sistema y población penitenciarios.}

Se registra una disminución en el número de procesados con prisión preventiva. Según información proporcionada por la Comisión Especial de Implementación del NCPP, con la aplicación del nuevo código se estaría promoviendo un nuevo estándar en el respeto de la libertad individual de las personas, acorde con la constitución política y los tratados internacionales en materia de derechos humanos. De 136,081 casos formalizados en los distritos judiciales en los que se aplica el NCPP, desde la entrada en vigencia en cada uno de ellos hasta el mes de marzo de $2010^{19}$, se presentaron 3,278 solicitudes de prisión preventiva, lo que equivale al $2.4 \%$ de los casos formalizados. Asimismo, del total de solicitudes atendidas $(3,278)$, se concedió prisión preventiva en el $75.8 \%$ $(2,485)$ de ellas.

Ha disminuido el número de presos sin sentencia y se ha incrementado el número de sentenciados. Según información también proporcionada por la Comisión Especial de Implementación del NCPP ${ }^{20}$, con la aplicación del nuevo código se registra una tendencia decreciente en el número de internos en calidad de procesados en los penales de los distritos judiciales en los que ha entrado en vigencia el nuevo código. En La Libertad, de 1,032 internos procesados al momento de la entrada en vigencia del NCPP (primero de abril de 2007), se pasó a 883 en 2008, sin perjuicio de un leve incremento de cuatro internos (887) en 2009, lo que ha implicado una disminución del 14\%, aproximadamente.

\section{Ha mejorado la confiabilidad en el nuevo sistema procesal penal.}

En mayo de 2010, la Comisión Especial de Implementación del NCPP reportó ${ }^{21}$ que el método de aplicación del nuevo código ha llevado a que se presente una mayor aceptación de los fallos por las partes, lo cual implica un menor uso de los recursos impugnatorios y de quejas. Todo ello podría traducirse como una mayor confiabilidad en el nuevo Sistema Procesal Penal.

19 "Proyecto de informe de resultados generales sobre el Código Procesal Penal». Ob. cit., pp. 2533. Este refiere que no ha comprendido los distritos judiciales de Ica y Cañete, así como los de Amazonas, Cajamarca y San Martín, por el poco tiempo de vigencia del NCPP. Por ello, el citado código entró en vigencia el primero de abril de 2010.

LA REFORMA PROCESAL PENAL EN EL PERÚ:

ROMPIENDO MOLDES, CONQUISTANDO METASY ENFRENTANDO PENDIENTES 


\section{Ha habido avances en la capacitación de los operadores para la aplicación del NCPP con respecto a la aplicación de soluciones alternativas y de oralidad.}

Con el apoyo de la GTZ, se ha generado una cultura de enseñanza por casos y simulacros a través de una metodología activa, sobre la base de la participación de los operadores y la discusión de casos prácticos. También se ha promovido, en los cursos, una participación interactuada de los distintos operadores del derecho (jueces, fiscales policías y abogados) para no separar en la capacitación (como ha ocurrido tradicionalmente) a quienes, en la práctica, deben interactuar.

Asimismo, se cuenta con una serie de manuales adecuados a las necesidades del ejercicio práctico del derecho procesal penal, además de con matrices de capacitación utilizadas por operadores y entidades de capacitación.

\section{La aplicación del NCPP en Huaura y La Libertad ha originado cambios positivos en la generación de información en el Poder Judicial, en el Ministerio Público y en la Defensoría de Oficio.}

Antes de la aplicación del NCPP, el registro estadístico prácticamente no existía en algunas instituciones (Defensoría de Oficio) y en otras, a pesar de estar incorporado, no se visualizaba como una tarea relevante (Poder Judicial y Ministerio Público). En Huaura y La Libertad, las instituciones mencionadas han incorporado la función de registro estadístico. En el caso del Poder Judicial, esta se encuentra a cargo de personal administrativo y, en el del Ministerio Público y la Defensoría, de los fiscales y defensores, respectivamente. Las tres entidades mencionadas han incorporado a sus nuevos o ya existentes sistemas de registro de información rubros relativos al NCPP: el Poder Judicial, por ejemplo, ha sumado nuevos criterios al Sistema Integrado Judicial Penal (SIJ), en tanto que el Ministerio Público ha reemplazado su anterior sistema por el Sistema de Gestión Fiscal (SGF) y la Defensoría ha desarrollado un sistema de control estadístico en Microsoft Excel ${ }^{22}$.

\section{Se ha avanzado con la diseminación de las ventajas de la aplicación del NCPP en el ámbito de la difusión.}

A la fecha, se han producido anuncios televisivos y radiales que serán difundidos en medios audiovisuales de los distritos judiciales implementados. Además, se ha elaborado material gráfico (banderolas, carteles y afiches) relacionados con la reforma procesal para distribuirse entre el público usuario, las fiscalías, las sedes descentralizadas de los distritos judiciales y ciertos puntos estratégicos. También se ha distribuido material 
impreso, se han realizado coordinaciones de protocolo y se han organizado ceremonias y actividades de difusión (pasacalles) ${ }^{23}$.

\section{Ha habido un importante acercamiento de los fiscales a las comunidades campesinas y nativas en el ámbito rural.}

Se han realizado encuentros y talleres de trabajo conjuntos, como el conducido en Amazonas, en el transcurso del presente $\mathrm{año}^{24}$.

\section{PRINCIPALES LIMITACIONES Y DESAFÍOS}

\section{La reforma procesal penal continúa siendo un proceso aislado, con bajo nivel de credibilidad ante la opinión pública ${ }^{25}$. Las demás reformas del sector no le han seguido el paso y, por lo tanto, están pendientes.}

La reforma del proceso penal no puede ser un proceso aislado: para cumplir a cabalidad sus objetivos y metas, debe insertarse en un proceso de mayor alcance, que involucre una reforma integral y comprensiva de la administración de justicia. Paralelamente a la transformación del proceso penal, debe operar en el país una reforma que conduzca al fortalecimiento del sistema de justicia en su conjunto. Si ambos procesos no coinciden, el avance en el área procesal penal, o en cualquier otra área del Derecho, será muy limitado.

Así lo entendió la Cooperación Alemana desde sus inicios. Por ello, consciente de la reciprocidad entre la reforma procesal penal y las otras reformas pendientes en el país, con gran acierto y perspicacia, amplió el asesoramiento de la reforma procesal penal a otras áreas claves de la reforma judicial. Brindó apoyo a dos iniciativas muy importantes en el campo de la reforma de la justicia del Perú: la CERIAJUS y el Acuerdo Nacional por la Justicia. Tras ello, apoyó el trabajo desarrollado por la Comisión Especial creada en el Congreso para dar seguimiento a las recomendaciones de la CERIAJUS, que estuvo en funciones hasta julio de 2006. De este modo, la Cooperación Alemana contribuyó a la elaboración y a la posterior aprobación por el pleno del Congreso de diferentes iniciativas legislativas para poner en práctica las citadas recomendaciones. Entre ellas se cuentan la Ley de Carrera Judicial y la Ley de Defensa Pública.

\section{Se carece de una política criminal de Estado que acompañe el proceso} de reforma procesal penal y también una política de fortalecimiento institucional de las entidades que participan en la prestación del servicio de justicia penal.

A pesar de los avances en el proceso de implementación de NCPP, no se percibe una política criminal que enmarque y oriente el curso de la

LA REFORMA PROCESAL PENAL EN EL PERÚ:

ROMPIENDO

MOLDES,

CONQUISTANDO METAS Y

ENFRENTANDO

PENDIENTES 
reforma procesal penal. Por otro lado, las instituciones de justicia todavía se perciben como frágiles, poco confiables y carentes de recursos humanos y materiales (medios, infraestructura y equipos) adecuados y suficientes.

\section{El cambio de mentalidad en los operadores del proceso penal es todavía un asunto pendiente.}

La implementación de la reforma procesal penal requiere una revolución del pensamiento, un cambio de mentalidad y de cultura organizacional en los operadores del nuevo proceso penal, ello dado que la reforma procesal penal no se limita a nuevas reglas y procedimientos, sino que implica que los funcionarios de las entidades cambien su concepción hacia un sistema de corte garantista y que dejen de lado la carga negativa del sistema inquisitorial.

El cambio de mentalidad es, sin lugar a dudas, uno de los desafíos más importantes para la efectiva y cabal implementación del nuevo proceso pena ${ }^{26}$. Ello se debe a que los operadores del sistema han sido formados y han estado trabajando bajo un sistema inquisitivo. Se requiere entonces, y de manera urgente, cambiar sus estructuras mentales y sus paradigmas para orientarlos hacia aquellos basados en la lógica del sistema acusatorio de la justicia penal.

Esto último solo podrá lograrse a través de intensos procesos y programas de formación, especialización y sensibilización de los operadores del sistema, y del compromiso e involucramiento de sus instituciones, del Estado y de la sociedad en general. Resulta fundamental la identificación de actores y líderes que podrían apoyar el proceso desde afuera y desde adentro de las entidades, tarea que podría ser realizada por las comisiones de implementación tanto a nivel nacional como a nivel local y distrital.

\section{Falta consolidar un liderazgo central y sólido en la gestión, monitoreo y control del cambio.}

No puede haber reforma efectiva y sostenible sin un gerenciamiento central y consistente en la gestión, el monitoreo y el control del cambio. Ello implica que debe contarse con:

- Una comisión nacional de implementación central con las facultades necesarias para la toma de decisiones, que trabaje de la mano y con el apoyo de los equipos de implementación de todas las entidades que participan en el proceso penal. La comisión debe contar con los medios necesarios para realizar su trabajo y articularlo armónicamente con las entidades del sistema de justicia (SAJ) y sus correspondientes equipos de implementación. Ello 
implica contar con un cronograma de actividades consensuando y actualizado con los respectivos responsables en cada entidad.

- Una línea de base sobre el estado de la cuestión en cada distrito judicial antes del inicio de la implementación del NCPP. Esto es básico para medir los avances y evaluar la incidencia efectiva del nuevo código en los procesos penales. La foto que logremos tomar antes del inicio del proceso de implementación también nos permitirá establecer metas y resultados concretos y viables dentro de los plazos fijados.

- Un marco lógico con establecimiento de objetivos, metas, resultados e indicadores realistas y adecuados a la realidad y a la situación de cada distrito judicial; además, un sistema consolidado y fluido de información, monitoreo y evaluación de la aplicación del NCPP, con encargados de evaluar paso a paso la marcha de los procesos tanto en el ámbito jurisdiccional como en el administrativo. La información dentro y fuera de las instituciones es un elemento clave. Medir y reportar los avances es vital para demostrar que el nuevo sistema funciona y que aporta al mejoramiento del servicio de justicia. Debe medirse el cumplimiento de objetivos, metas, resultados y plazos; la adecuación y suficiencia de los recursos económicos asignados y disponibles; los avances, logros, limitaciones y obstáculos. Y deben detectarse los problemas y los cuellos de botella, así como anticiparse los riesgos y los correctivos necesarios. Asimismo, se deberá prestar especial atención al funcionamiento de las entidades y a la productividad de sus funcionarios. También se analizará la capacidad (medida en cantidad de casos) y la calidad de las resoluciones y de las actuaciones de cada tipo de operador (juez, fiscal, defensor, policía). A tal efecto, como paso previo, deberá determinarse la productividad esperada, la carga de trabajo y la duración promedio de los casos (por tipos de delito, por complejidad, por número de involucrados, por zona geográfica, etcétera). A partir de allí, podrá llevarse control sobre la duración promedio de las actuaciones relevantes de los operadores y, por ende, de la duración de los casos y de la efectividad de la implementación del nuevo sistema procesal penal.

- Una constante retroalimentación de las experiencias de implementación de la reforma en las decisiones político-institucionales a medida en que la reforma es introducida en nuevos distritos judiciales. La implementación del nuevo sistema y de las reformas en los primeros distritos judiciales debe servir como un centro de aprendizaje para capitalizar experiencias e instruirse de los aciertos y desaciertos, y de los avances y los tropiezos. Las experiencias exitosas tienen mucho valor, ya que ayudan a «vender» el sistema y sus beneficios y pueden, además, ser replicadas en los demás distritos judiciales: de allí la importancia de documentarlas 
y difundirlas. Esto resulta de trascendental importancia dada la cada vez mayor complejidad que reviste la implementación de la reforma procesal penal al extenderse progresivamente a distritos judiciales más populosos, heterogéneos y con mayor carga procesal.

\section{Aún no se cuenta con una adecuada y moderna gestión y organización en el interior de las instituciones del sistema de justicia penal para la implementación del NCPP.}

La aplicación de la oralidad como metodología de trabajo en el proceso penal requiere necesariamente la implantación de un sistema de audiencias como eje central del proceso, cuyo óptimo funcionamiento necesita de una adecuada y moderna gestión y organización dentro de las instituciones del sistema de justicia penal, campo en el cual todavía se ha avanzado muy poco ${ }^{27}$.

\section{Las capacidades de los operadores para aplicar el NCPP requieren ser fortalecidas. La formación del profesional del Derecho debe ser una preocupación constante y central de la reforma.}

Si bien se ha avanzado en la capacitación de los operadores para la implementación del NCPP, aún queda mucho por hacer. Se requiere no solo intensificar y ampliar la capacitación hacia nuevos distritos de aplicación del NCPP, sino también fortalecer las destrezas y habilidades técnicas de los operadores de los distritos judiciales donde viene aplicándose, sobre todo en: (a) temas ejes del nuevo proceso penal, como técnicas de litigación oral, técnicas de investigación criminal y criminalística, aplicación de salidas alternativas y mecanismos de descongestión; y en (b) aspectos clave para un buen desempeño en el nuevo sistema, como por ejemplo manejo de tiempo y conflicto, negociación, conciliación, presentación oral de argumentos e ideas, uso de la facultad de calificar y archivar las denuncias, entre otros.

Se requiere también de la especialización de nuevos formadores que, en el futuro, asumirán la capacitación de los operadores del proceso penal. En este campo, las universidades y las escuelas de capacitación juegan un rol fundamental.

En cuanto a la metodología de capacitación, es fundamental la consagración de patrones análogos para el entrenamiento de todos los operadores del Derecho. Debe promoverse su capacitación conjunta y desplegarse un mayor esfuerzo para desarrollar programas de capacitación que, articulados con las cuatro instituciones eje (jueces, fiscales, defensores públicos y policía), permitan prepararlos con la debida anticipación a la vigencia del NCPP. 
También resulta fundamental consolidar el sistema de capacitación por casos y simulacros desarrollado e impulsado por la Cooperación Alemana. Estos últimos son instrumentos clave de formación para nuevos operadores, en vista de que la interacción y el diálogo entre los actores del proceso beneficia la absolución de dudas, la detección y la superación de obstáculos y cuellos de botella, y la implementación de correctivos y cambios necesarios para optimizar la implementación de la reforma procesal penal.

De igual modo, es necesario intensificar la elaboración y la distribución de materiales e instrumentos de apoyo a la capacitación, como manuales y guías (documentales o videos), y también de matrices de capacitación para ser usadas por capacitadores, formadores y diferentes entidades de capacitación.

\section{Se carece de guías y manuales de actuación como instrumentos de apoyo y orientación para el ejercicio práctico del Derecho procesal penal.}

Así, por ejemplo, se percibe una falta de protocolos de actuación para la labor de investigación, lo cual genera deficiencias y retrasos en dicha labor. Asimismo, se deben uniformizar y estandarizar criterios de actuación y de toma de decisiones aplicables en casos y situaciones similares ${ }^{28}$.

\section{Se carece de una política de asignación de recursos humanos y materiales para la aplicación del NCPP que tenga en cuenta las peculiares características y necesidades de cada distrito judicial.}

Ante las particularidades de cada distrito judicial, que varían en tamaño, complejidad, acceso, comunicación, servicios básicos, población, carga procesal, tipos de delitos más frecuentes, entre otros factores, una óptima asignación de recursos debe partir de un análisis puntual de la realidad de cada uno, de sus requerimientos y necesidades, y también de sus fortalezas y oportunidades. Sin ello, no puede garantizarse que las entidades de cada distrito judicial reciban recursos suficientes y adecuados para aplicar el NCPP.

En general, se perciben muchas carencias de infraestructura y de logística. Muchas salas de audiencia del Poder Judicial son aún muy estrechas e inadecuadas para actuaciones judiciales, eje de la fase de juzgamiento ${ }^{29}$.

\section{Subsisten barreras para fluidas comunicación y coordinación entre las instituciones de justicia que participan en el proceso penal.}

Deben superarse las barreras de comunicación y concertación entre las instituciones de justicia involucradas en el proceso penal. Hoy, más que nunca, se requiere un intercambio regular e interinstitucional de

LA REFORMA PROCESAL PENAL EN EL PERÚ:

ROMPIENDO MOLDES,

CONQUISTANDO METAS Y ENFRENTANDO PENDIENTES 
análisis y comparación de experiencias en la aplicación del NCPP, pues los nuevos procesos demandan una amplia y continua interacción a nivel de dirección, gerencia y operaciones.

Se necesita promover sistemas informáticos que permitan a las instituciones compartir información y bases de datos. También se requiere consolidar espacios de concertación para el intercambio de información y la coordinación necesaria, para limar diferencias y disputas; y promover un proceso de articulación entre el Ministerio Público y la Defensoría de Oficio, para coordinar la aplicación de las salidas alternativas, que aún generan reticencia en los defensores públicos ${ }^{30}$.

En suma, se necesita sensibilizar y desarrollar capacidades de trabajo coordinado e interinstitucional a nivel nacional y entre los distritos judiciales en aras de una efectiva implementación del NCPP.

\section{Se requiere mejorar la divulgación y la difusión del proceso de implementación de la reforma procesal penal.}

Una buena estrategia comunicacional, orientada a una efectiva divulgación de la reforma procesal penal, debe dar a conocer el porqué de la reforma, su punto de partida, los resultados esperados y alcanzados, y los costos y beneficios que ella implica. También se requiere de una amplia difusión de las experiencias exitosas para que puedan ser replicadas y transferidas y, con ello, evitar que los mismos errores sean cometidos en otros distritos judiciales y en otras áreas de reforma. Esta iniciativa permitirá que los ciudadanos perciban los efectos positivos del nuevo sistema procesal penal a través de la difusión de resultados concretos y fácilmente perceptibles, como la disminución de la duración de los procesos, de la carga procesal, del hacinamiento carcelario y de presos sin sentencia, de apelaciones, de quejas ante las oficinas de control disciplinario de los jueces y fiscales, etcétera.

Las actividades de comunicación y los instrumentos utilizados para la difusión deben ser definidos y organizados en función de los públicos meta y deben llegar al conjunto de la ciudadanía. Es importante que la población esté bien orientada, que perciba con claridad los mensajes y que se movilice apoyando la implementación de las reformas. Para ello, resulta fundamental orientar a los ciudadanos sobre sus derechos y obligaciones durante el proceso, así como sobre las instancias a las cuales pueden recurrir para absolver dudas, realizar trámites o presentar quejas.

\section{Hace falta una mejor sistematización y documentación de los procesos de implementación.}

La documentación y sistematización de los procesos de implementación, de las experiencias vividas, de los obstáculos encontrados, de las decisiones tomadas y de las soluciones adoptadas es crucial para dos cometidos: 
(a) optimizar y consolidar la implementación del NCPP en los distritos donde viene aplicándose; y (b) lograr una mejor y más efectiva implementación del NCPP en los nuevos distritos judiciales.

\section{Falta mayor atención, apoyo y asistencia técnica hacia la Policía Nacional para la implementación del NCPP.}

Se requiere prestar especial atención y apoyo a la Policía Nacional, ya que se ha podido constatar que todavía existe una fuerte resistencia por parte de sus miembros hacia la vigencia del NCPP. En la práctica, se percibe una superposición entre las funciones del Ministerio Público y las de la Policía Nacional respecto de la investigación del delito ${ }^{31}$.

Por otro lado, dado que la policía es la principal o única fuente para conocer el desenvolvimiento de los delitos a nivel nacional, regional y local, preocupa que esta no haya modificado sus sistemas tradicionales de acopio y de sistematización de información a partir de la vigencia del CPP. La policía carece de un sistema de registro único integrado de información: por ejemplo, algunos homicidios pueden ser investigados por la Dirección de Investigación Criminal (DIRINCRI) y otros por las Direcciones Territoriales de Policía (DIRTEPOLES), y sus respectivas estadísticas no forman parte de un solo documento cuantitativo ${ }^{32}$.

\section{El desarrollo de la infraestructura debe prestar mayor atención a las necesidades de los usuarios.}

En el proceso de construcción y de adecuación de nuevos locales para la prestación del servicio de justicia, debe tomarse en cuenta las necesidades de los usuarios, que son con frecuencia olvidadas o minimizadas. Por ejemplo, no debe perderse de vista la importancia de contar con salas de espera adecuadas, servicios higiénicos en buen estado, servicios de información y orientación, facilidades para formular consultas, entre otros.

\section{Falta implementar un programa de descarga procesal penal que facilite la liquidación de causas bajo el sistema anterior.}

Esto es fundamental en distritos judiciales con un gran volumen de carga procesal acumulada, como Lima, Callao y Cono Norte. De lo contrario, el proceso de liquidación se torna bastante lento y engorroso.

\section{Falta desarrollar una reingeniería de procesos y una simplificación administrativa acordes con el nuevo sistema procesal penal, además de prestar más atención a la adecuación y al fortalecimiento de los sistemas tecnológicos.}

Se debe analizar y determinar la pertinencia y la necesidad de ciertos trámites, documentos, certificaciones, fotocopias, archivos y demás, que aún son el pan de cada día de las entidades del sistema de justicia. Su

LA REFORMA PROCESAL PENAL EN EL PERÚ:

ROMPIENDO MOLDES, CONQUISTANDO METAS Y ENFRENTANDO PENDIENTES 
objetivo es simplificar, adecuar, agilizar, hacer más efectivos y también menos onerosos los procesos y las actuaciones (en términos de tiempo y dinero), así como de sacar el máximo provecho a las ventajas de oportunidad y celeridad que ofrece el nuevo sistema procesal penal.

Al mismo tiempo, a pesar de los avances en el campo de los sistemas tecnológicos, todavía queda mucho por hacer para lograr sistemas integrados de registro de casos y de actuaciones entre las entidades del Sistema de Administración de Justicia. Las entidades deben hacer esfuerzos para integrar agendas de actuación de jueces, fiscales y defensores. Solo así se podrá asegurar la realización de las audiencias y evitar cuellos de botella que atentan contra la oportunidad y la celeridad de los procesos.

\section{Falta prestar mayor atención a la diversidad cultural del país y a la coexistencia de diferentes instancias de resolución de conflictos, sobre todo a nivel rural.}

La falta de éxito de algunas reformas obedece a que no han conseguido llegar ni atender a todos los ámbitos y estratos de la población peruana, debido a que no consideraron en su diseño la gran diversidad cultural y la realidad de las diferentes instancias de resolución de conflictos, sobre todo en las zonas rurales. Ante ello, quedan al margen de los beneficios de la reforma importantes segmentos del país, que cuentan con una estructura diferente y requieren, por lo tanto, de una dinámica distinta.

La implementación de la reforma procesal penal en áreas rurales debe prestar especial atención a sus características especiales y particulares, y considerar fórmulas creativas que integren al poblador rural y que le garanticen el ejercicio de sus derechos y el acceso a la justicia. Así se articularán los sistemas de justicia estatal y comunitaria.

El propio Ministerio Público ha reconocido que un aspecto importante aún pendiente en la implementación de la reforma procesal penal es la capacitación de las comunidades indígenas y nativas, a fin de integrarlas al nuevo sistema procesal ${ }^{33}$.

\section{REFLEXIONES FINALES}

Tras este sucinto análisis sobre los principales alcances y aportes, resultados y logros, limitaciones y desafíos de la implementación de la Reforma Procesal Penal en el Perú, podemos llegar a tres reflexiones finales:

1. El NCPP representa un importantísimo avance en la justicia penal peruana, cuyas bondades pueden y deben replicarse en otros ámbitos de la administración de justicia. 
2. A la fecha, su vigencia e implementación en más de la mitad de los distritos judiciales del país ya hace sentir sus logros y su impacto en temas críticos y cruciales de la justicia peruana, tales como mayor celeridad en los procesos judiciales y la consiguiente reducción en su duración, desjudicialización de las causas, aplicación de salidas alternativas y terminación anticipada de los procesos, disminución de carga procesal, mayor razonabilidad en la aplicación de la prisión preventiva, disminución de presos sin sentencia y mayor confiabilidad en el sistema de justicia, entre otros.

3. No obstante, aspectos muy importantes del nuevo sistema procesal penal aún deben ser mejorados y fortalecidos sin demora en el todavía largo camino por recorrer. Afortunadamente estamos a tiempo, pues el NCPP todavía no ha iniciado su vigencia en los distritos judiciales más complejos y con mayor carga procesal: Lima, Callao y el Cono Norte. Estos requieren de un sistema procesal penal más maduro, que les permita afrontar los mayores desafíos que le merece su especial complejidad, alto nivel poblacional, gran diversidad y elevada carga procesal.

LA REFORMA

PROCESAL PENAL

EN EL PERÚ:

ROMPIENDO

MOLDES,

CONQUISTANDO

METAS Y

ENFRENTANDO

PENDIENTES 